\title{
Paciente laringectomizado total: perspectivas para a ação clínica do psicólogo ${ }^{1}$
}

\author{
Leopoldo Nelson Fernandes Barbosa ${ }^{2}$ \\ Universidade Federal de Pernambuco, Recife-PE, Brasil \\ Ana Lúcia Francisco \\ Universidade Católica de Pernambuco, Recife-PE, Brasil
}

\begin{abstract}
Resumo: A cirurgia de laringectomia total implica a necessidade de procedimentos agressivos e provoca lesões estéticas e funcionais irrecuperáveis, acarretando repercussões biopsicossociais. Por meio de pesquisa de natureza qualitativa foram investigadas as repercussões psicossociais na construção subjetiva de pacientes laringectomizados e de seus cuidadores. O percurso do adoecimento é vivido como um momento de crise em que predomina o sentimento de desamparo e desalojamento. A perda da fala pode levar o paciente a isolar-se socialmente, afastar-se de suas funções profissionais, com sentimentos de vergonha e culpa, provocando intensa angústia e sofrimento. Os cuidadores sofrem diante da possibilidade da perda de um ente querido e, também, por tentativas, nem sempre bem sucedidas, de dar suporte e oferecer ambiência para as novas necessidades que se apresentam. Os resultados evidenciam que conhecer as repercussões psicossociais dessa experiência pode fornecer importantes subsídios para a psicologia clínica.
\end{abstract}

Palavras-chave: laringectomizados, cuidadores, psicologia clínica.

\section{Total laryngectomized patient: perspectives for the psychologist's clinical action}

\begin{abstract}
Total laryngectomy surgery implies aggressive procedures that cause irretrievable esthetic and functional injuries, causing a series of biopsychosocial implications. Through a qualitative research, we have investigated psychosocial repercussions in the subjective construction of laryngectomized patients and their caregivers. The path through illness is experienced as a moment of crisis in which abandonment and destitution feelings prevail. The loss of speech may lead patients to social isolation, deviation from professional functions, with feelings of shame and guilt, leading to anguish and suffering. Caregivers suffer not only due to the possibility of a loss, but also because of their attempts, nor always successful, to give support and offer ambience for new necessities that appear. Results show that knowing psychosocial repercussions of this experience may provide important subsidies to clinical psychology
\end{abstract}

Keywords: laryngectomees, caregivers, clinical psychology.

\section{Paciente laringectomizado total: perspectivas para la acción clínica del psicólogo}

Resumen: La cirugía de laringectomía Total implica la necesidad de procedimientos agresivos que causan lesiones estéticas y funcionales irrecuperables y una serie de consecuencias biopsicosociales. Por una metodología cualitativa investigamos las repercusiones psicosociales posibles en la construcción subjetiva de pacientes laringectomizados y sus cuidadores. Todo el pasaje alrededor de la enfermedad es vivido como un momento de crisis donde el sentimiento de abandono predomina. La pérdida de la habla asume prioridad, conduciendo el paciente para aislarse de su cordialidad social, marcharse de sus funciones profesionales, con sentimientos inadecuados, estima propia baja, vergüenza y culpa. La familia sufre doblemente: de un lado por la percepción de la fragilidad y el temor de la pérdida y de otro por tentativas, ni siempre exitosas, para dar apoyo y ofrecer el ambiente para las nuevas necesidades que se presentan. Conocer las repercusiones psicosociales de esa experiencia puede traer importantes subsidios para la psicología clínica

Palabras clave: laringectomizados, cuidadores, psicología clínica.

Atualmente, o câncer é reconhecido como um problema de saúde pública e representa $12 \%$ das causas de mortes em todo o mundo. Nessa projeção, o câncer de laringe representa $2,7 \%$ de todos os casos de câncer, sendo responsável por 2,2\% dos óbitos (Ministério da Saúde, 2007). De acordo com o

\footnotetext{
${ }^{1}$ Apoio: PROSUP/CAPES. Trabalho derivado da Dissertação de Mestrado do primeiro autor, sob a orientação da segunda autora, desenvolvida no Programa de Pós-graduação em Psicologia Clínica da Universidade Católica de Pernambuco. Este texto foi revisado seguindo Acordo Ortográfico da Língua Portuguesa (1990), em vigor a partir de $1^{\circ}$ de janeiro de 2009.

${ }^{2}$ Endereço para correspondência:

Leopoldo Nelson Fernandes Barbosa. Av. Beira Rio, 230/101. Ilha do Retiro. CEP 50.750-400. Recife-PE, Brasil.E-mail: lnfbpsi@uol.com.br
}

Instituto Nacional de Câncer (2005), este tipo de câncer é um dos mais comuns na região da cabeça e pescoço, representando $25 \%$ dos tumores malignos que acometem esta área e $2 \%$ de todas as doenças malignas.

A partir dessa estimativa, a Sociedade Brasileira de Cancerologia - (2007) afirma que, aproximadamente, 80\% dos tumores nessas regiões continuam chegando às mãos de especialistas em estágios já avançados, o que significa custos financeiros para o sistema de saúde e pesados ônus, também humanos, para os pacientes e familiares. Diante de evidências que podem ser prevenidas, diagnosticadas precocemente, tratadas e curadas, as metas educativas devem ser focadas no alerta à população no que diz respeito aos fatores de risco, em especial, tabagismo e alcoolismo. 
De modo geral, em pacientes com Câncer de Cabeça e Pescoço (CCP) são observadas demandas bastante diferenciadas e que dependem, sobretudo, do contexto social (Derks, Leeuw, Hordijjk, \& Winnbust, 2005). Nessa perspectiva, tornase importante que a equipe de saúde possa identificar as reais necessidades dos pacientes e de seus familiares/cuidadores para direcionar o suporte necessário.

As repercussões do câncer de laringe realmente causam grande impacto e, em geral, os procedimentos afetam a autoimagem, modificam a anatomia funcional, incidindo diretamente na respiração, na alimentação e na comunicação oral. Dessa forma, as alterações estéticas e funcionais podem acarretar um profundo sentimento de estar desalojado, interrompendo projetos de vida, gerando graves consequências para os familiares e pessoas próximas envolvidas no cuidado aos pacientes.

No caso da laringectomia total (LT), tratamento clássico no câncer de laringe, a retirada total do órgão e de seus acessórios e a implantação de um traqueostoma definitivo na parede do pescoço, para que o paciente possa respirar (Gonçalves, Menezes, \& Bertelli, 2005), implicam em significativas alterações em todo o contexto do paciente, envolvendo aspectos biopsicossociais.

Em nossa cultura, por exemplo, a comunicação oral é reconhecida como um importante veículo de inserção e convívio social. Na reabilitação do laringectomizado, além de um dos objetivos mais almejados (Flávio \& Zago, 1999), a comunicação oral é reconhecida como um aspecto relevante e prioritário no cuidado dirigido ao paciente (Barbosa, Santos, Amaral, Gonçalves, \& Bruscato, 2004). Diante disso, Gonçalves e cols. (2005) relatam que a reabilitação da voz pode ser realizada a partir da utilização de prótese traqueo-esofágica, de laringe eletrônica e/ou da voz esofágica, fazendo-se necessária a reabilitação fonoterápica.

De fato, qualquer paciente que vivencie um tratamento envolvendo cirurgia, quimioterapia e radioterapia fica bastante debilitado. Lotempio e cols. (2005) relatam que após a LT, além da perda da voz, o paciente depara-se com o desfigurado anatômico devido à traqueostomia, apresenta dificuldades para mastigar e engolir certos alimentos, podendo sentir-se embaraçado em público ou impedido de desenvolver algumas de suas atividades diárias. Complementando, Braz, Ribas, Dedivitis, Nishimoto e Barros (2005) destacam as significativas alterações no olfato e paladar e a tosse que comumente acompanha o paciente no pós-cirúrgico.

Acompanhar o paciente antes e após o tratamento, de maneira adequada e esclarecendo dúvidas, pode reduzir o tempo de internação, diminuir a dor e aumentar a satisfação com o tratamento (Birgin, 2004; Ramírez e cols., 2003). Devido à visibilidade da sua localização e ao envolvimento de funções essenciais no desenvolvimento de atividades pessoais e no convívio social, o real impacto da LT só é vivido após a sua completa ocorrência. Dessa forma, faz-se necessário que o paciente receba informações adequadas sobre a doença e todo o tratamento.
Embora muitas pesquisas venham sendo desenvolvidas na área de oncologia, em relação ao câncer de laringe, poucos estudos abordam a ação do psicólogo junto a pacientes laringectomizados. Com o intuito de contribuir para o aprofundamento dessa temática, objetivamos, através desta pesquisa, investigar as repercussões psicossociais geradas por este quadro clínico, bem como refletir sobre as possibilidades de práticas psicológicas que possam minorar o sofrimento de pacientes que se submetem a laringectomia total e de seus familiares.

De forma específica, procuramos caracterizar as mudanças ocorridas no cotidiano desses pacientes, em suas relações familiares e sociais, com o intuito de compreender como estas mudanças afetam o equilíbrio emocional das pessoas envolvidas em todo o processo e quais suas estratégias de enfrentamento psicológico.

\section{Método}

Esta pesquisa utilizou metodologia qualitativa, baseada na narrativa dos participantes e em observações realizadas no atendimento a esta clientela, registradas em um diário de bordo. Nessa perspectiva, o desenho do estudo, caracterizado como descritivo transversal, permite uma compreensão, simultaneamente global e singular, da experiência de submeter-se à LT. Como dito por Minayo (2004), esta metodologia preocupa-se menos com a generalização dos resultados, permitindo a atenção ao específico, peculiar, singular, buscando uma compreensão abrangente e profunda do fenômeno.

\section{Participantes}

Foram convidados a participar da pesquisa seis pacientes laringectomizados, cujo contato foi realizado por intermédio do setor de fonoaudiologia de um hospital público de referência para atendimento oncológico das regiões norte e nordeste do Brasil. Por ocasião das entrevistas com estes pacientes, foi solicitada a indicação de seu cuidador mais próximo para que pudéssemos, também, ouvi-lo, com o intuito de compreender como a família reage e lida com o sofrimento do paciente e suas limitações.

Com base na revisão da literatura e de acordo com os objetivos da pesquisa, foram incluídos os pacientes que realizaram a cirurgia de LT por câncer de laringe e que estivessem reabilitados com a voz esofágica, utilizassem prótese tráqueoesofágica ou laringe eletrônica. Por se tratar de uma instituição pública e pela maioria dos laringectomizados optar pela voz esofágica, principalmente pelo seu baixo custo, estabelecemos, de acordo com Nemr e Ramozzi-Chiarottino (2002), o período mínimo de seis meses de reabilitação fonoaudiológica após a realização da cirurgia.

Como critérios de exclusão, não foram incluídos os pacientes com presença de metástases ou recidiva loco-regional, pois, de acordo com Arrànz e Coca (2003), o agravamento do quadro leva o paciente a uma nova vivência de crise e necessidade de 
re-adaptação; também foram excluídos pacientes com deficiência mental grave, demência ou psicose, deficiência auditiva grave, sequelas neurológicas de Acidente Vascular Cerebral (AVC), dadas as implicações éticas de pesquisas com essa população.

A faixa etária dos pacientes laringectomizados variou de 48 a 77 anos, sendo quatro homens e duas mulheres. Dos seis participantes entrevistados, apenas quatro autorizaram o contato com o principal cuidador, o que, dado o caráter qualitativo da pesquisa, não inviabilizou a proposta de ouvi-los em sua experiência como acompanhantes. Duas das cuidadoras participantes eram esposas e duas eram filhas dos pacientes.

\section{Considerações éticas}

A pesquisa, realizada no período de janeiro a abril de 2007, foi iniciada após autorização do Comitê de Ética do hospital selecionado para o desenvolvimento da pesquisa, respeitando-se as diretrizes constantes na Resolução CNS 196/96. Os pacientes foram entrevistados somente após a leitura, compreensão e assinatura do Termo de Consentimento Livre e Esclarecido. Nessa ocasião, solicitou-se autorização para a gravação das entrevistas.

\section{Procedimentos}

Coleta de dados

Como recurso metodológico, utilizamos uma entrevista semi-estruturada, visando à apreensão da experiência vivida, a qual teve como frase estímulo: "O que aconteceu na sua vida após a cirurgia de laringectomia total?". As entrevistas foram realizadas pelo próprio pesquisador, individualmente, com cada participante.

Apesar de reabilitados, alguns dos participantes apresentavam voz bastante áspera e grave, motivo pelo qual, para uma melhor compreensão da voz dos participantes e transcrição integral das falas, optamos por, antes da transcrição, trabalhar as entrevistas para amplificá-las em um editor de áudio.

Com a finalidade de manter o anonimato dos participantes, suas narrativas serão seguidas da indicação laringectomizada, laringectomizado e por cuidadora, respectivamente

Com o objetivo de preservar as falas dos participantes, utilizou-se, na transcrição, a padronização de que os parênteses indicariam comportamentos não verbais, como o silêncio e o choro. Consideramos importante essa marcação para que o leitor possa se aproximar um pouco da intensidade dos relatos.

\section{Análise dos dados}

Após a transcrição das entrevistas e de sua leitura, visando a uma maior aproximação com o conteúdo das falas, foram estabelecidos eixos temáticos para nortear a discussão. Levando em consideração a perspectiva clínico-qualitativa proposta por
Turato (2003), os dados foram divididos em categorias, expondo-se fragmentos de falas como forma de ilustrar os dados submetidos à análise.

\section{Resultados e Discussão}

Em processos de adoecimento e de hospitalização é bastante comum haver o confronto com a precariedade de nossa condição humana e da instabilidade do mundo. Para Barbosa, Francisco e Efken (2007), estes são momentos "privilegiados" em que nos deparamos com o contingente, com a finitude e com a privação de liberdade, impulsionando-nos a refletir sobre o real sentido da vida. O que também se observa é que muitas dessas reflexões modificam conceitos, metas, objetivos e posturas pessoais em torno da própria existência. Reflexões que necessitam ser faladas e ouvidas e, talvez, essa seja uma das principais funções do psicólogo no contexto hospitalar: cuidar, colocar-se à escuta do que não quer se calar e ouvir a denúncia despertada pelo sofrimento que está para além do adoecimento de um corpo.

$\mathrm{O}$ adoecimento sinaliza a possibilidade de, prematuramente, romper ou nos separar do real e chega a nos interrogar sobre o que fazemos, fizemos e/ou poderíamos ter feito da nossa vida; na maioria das vezes é vivido com um verdadeiro "golpe do destino". Nessa perspectiva de imprevisibilidade e impacto e diante da possibilidade de poder acolher esse tipo de sofrimento, somos convocados a encarar a nossa "curta" vida e refletir sobre o hoje para que o amanhã não seja apenas preenchido de "nunca mais", paralisando, impedindo ou limitando a nossa existência. Além disso, compreender a doença, as representações culturais e os estigmas sobre ela parecem indispensáveis, principalmente quando estão presentes registros negativos que algumas doenças trazem e, nesse caso, a vivência de um câncer.

Mudou tudo (...) eu fiquei com desgosto, sofrendo, fiquei mais nervosa. Hoje eu não falo muito, sofro dos nervos. Eu me sinto mais só porque antes ia pra todo canto e depois tinha que ter alguém porque ninguém entendia a minha voz. (...) Eu choro. Eu fico nervosa e choro, choro muito. Ontem, quando eu vim pra cá, fiquei a manhã toda com vontade de chorar. Eu não tô conseguindo desabafar, tô ficando nervosa (...) tô tomando também diazepan e remédio pra depressão (laringectomizada).

No decorrer das entrevistas, entre os diversos aspectos vivenciados em uma situação de sofrimento, dor e vulnerabilidade, comumente atrelados ao adoecimento, o confronto com a possibilidade de morte foi evidenciado como um dos principais focos de desequilíbrio emocional do paciente. Muitas vezes, esse confronto foi mantido em segredo ou interditado pela família, pela equipe de saúde ou pelo próprio paciente, parecendo, de uma forma geral, ser quase proibido falar sobre isto em um hospital. Em muitos casos, essa presença-ausente, 
silenciada "de morte" pode causar reações físicas, tais como ansiedade excessiva, humor deprimido, entre outros que se estendem aos cuidadores e familiares e podem tornar a experienciada hospitalização ainda mais atroz.

Como forma de apaziguamento da ansiedade vivida, laringectomizados e cuidadores buscam causas e/ou justificativas para o seu sofrimento, talvez, como uma tentativa de racionalizar suas emoções ou mesmo de minimizar responsabilidades e culpas frente ao quadro clinico: "Eu fumava muito. Fumava três maços por dia (...) eu fumava muito" (laringectomizada) e

O Sr. sabe que ela bebia e fumava, não é? Ela começou a ficar rouca (...) Muito rouca, aí ela parava com o cigarro, ficava melhorzinha. Ai começava tudo de novo, a beber e fumar, fumava mais do que devia (cuidadora).

Nessa direção, na tentativa de avaliar diferentes estratégias e modos de enfrentamento de pacientes com CCP, Derks e cols. (2005) realizaram um estudo com 183 pacientes, dos quais 78 tinham idade igual ou superior a 70 anos e 105 pacientes com idades variando entre 45 e 60 anos. Os resultados indicaram que os pacientes a partir dos 70 anos que fumavam e bebiam se sentiam mais culpados, enquanto os pacientes com idade abaixo dos 60 anos colocavam no tabagismo e no uso do álcool a causa de sua doença, resultando, nos dois grupos, no aparecimento de sintomas depressivos que interferiam no tratamento, a médio e longo prazo.

Barbosa e cols. (2004), Björklund, Sarvima e Berg (2008) e Santana, Zanin e Maniglia (2008) seguem uma perspectiva que sugere uma maior possibilidade de "amparo" frente à vivência da intensidade dessas repercussões, na medida em que o paciente possa dispor de uma rede de suporte mais favorável que engloba aspectos profissionais, sociais e familiares. Como dito por Noto e Galduróz (1999), embora as ações preventivas no Brasil não sejam tão tradicionais, esse panorama vem sendo modificado e aponta para o surgimento de uma nova tendência. Além disso, Ismael (2007) acrescenta que o Brasil vem se destacando mundialmente, por exemplo, em programas de prevenção e intervenção no combate ao fumo.

No caso dos pacientes que se submetem a LT, observamos repercussões inerentes à doença que estão presentes desde o momento do diagnóstico, do subsequente tratamento invasivo e mutilante, acompanhado da dolorosa experiência de hospitalização. Entretanto, o hospital, apesar de etimologicamente ser reconhecido como "casa de hóspedes" ou "casa de abrigo", ao mesmo tempo em que abriga para cuidados, desaloja o paciente de um contexto de segurança. Estar em um hospital é sinal de que algo não está bem e nos conecta diretamente com a nossa condição humana de um ser finito. Frequentemente essa é uma situação que nos aproxima de reflexões internas mais intensas e que, em muitos momentos, repercute em mudanças no modo de viver do paciente, de seus cuidadores, dos familiares e de pessoas próximas.
É muito desconfortável ficar aqui e eu acho que nem só pra mim, mas pra todos que vem (...) é porque eu vejo muita gente doente, muita coisa feia e como eu senti dele. Eu acho que as outras famílias sentem dos outros, né? Sei lá (...) em todo hospital é assim mesmo (...) aqui é pior porque a gente vê mais coisa grave (...) essas doenças (...) mas ele foi bem atendido aqui (cuidadora).

Cada paciente e cada cuidadora e familiar experimentava e reagia às situações de modo diferenciado, o que nos leva a problematizar a padronização de técnicas e conceitos a respeito da doença, do doente e do tratamento, na medida em que podem tanto aprisionar a nossa forma de ver a pessoa que sofre quanto nos impedir de ouvir o que realmente se passa; ouvir um ser em devir. A esse respeito e abordando a questão da convivência, Schettini (2007) destaca que a forma individual de expressão é o modo mais rico de cada um aparecer no mundo. A cada momento que aparecemos, para nós e para os outros, somos a mesma pessoa, porém, com uma forma peculiar de ser pessoa para cada circunstância. “(...) É por isso que para sermos os mesmos precisamos estar mudando sempre dentro da nossa configuração de pessoa" (p. 18).

Vale ressaltar que, em pacientes com CCP, é importante poder avaliar variáveis ligadas ao modo de enfrentamento, rede e apoio social (Santana e cols., 2008). Até mesmo porque a maioria dos pacientes e dos seus cuidadores pode enfrentar dificuldades emocionais e fatores associados à diminuição da sua qualidade de vida (Barbosa e cols., 2004; Derks e cols., 2005; Ramírez e cols., 2003; Vickery, Hewinson, Bellew, \& Feber, 2003).

O tratamento mexe na rotina e às vezes não tenho coragem de vir. Quando eu tô nervosa eu não tenho vontade de vir e as pessoas quando eu chego também percebem que eu fico assim (...) diferente. (...) Eu tenho nervoso de ir pro médico e tenho que vir com a minha filha. Foi ele que disse pra eu fazer a cirurgia (...) Quase morro depois da operação sem poder respirar, teve uma vez que entupiu [referindo-se à traqueostomia] e eu fiquei sem respirar mesmo. Hoje eu até acho graça, mas foi difícil (laringectomizada).

Enquanto ser em devir, em relação às experiências - boas ou más - que acontecem nessa caminhada, é a precariedade que revela a importância de um lugar para repouso, um lugar onde se possa realmente "estar", pois somente a experiência de estar lançado ao mundo marca a necessidade desse lugar, tão necessário à condição humana (Safra, 2006a). A nossa experiência clínica com pacientes oncológicos e que se submetem aos procedimentos invasivos de uma LT demonstra que o registro de uma verdadeira "sentença de morte" que acompanha essa doença, não raro, causa um sentimento tão profundo de angústia que parece não ter contornos, chegando mesmo a tornar-se agonia e desalojamento, tanto nos pacientes quanto em seus 
Barbosa, L. N. F., \& Francisco, A. L. (2011). Laringectomizados: ação do psicólogo.

cuidadores. O registro que fica não é do medo de "simplesmente morrer", mas sim o de "morrer de câncer", dado o seu estigma e representações negativas construídas ao longo dos séculos: "Muitos diziam pra ela comprar o caixão porque isso era morte certa (...) Diziam pra ela comprar o caixão porque dessa eu não escapava... mas outros diziam pra ela ter fé em Deus" (Laringectomizado).

Segundo os clássicos da filologia, cuidado deriva do latim “cura”. Mas também significa cogitar, pensar, colocar atenção, mostrar interesse, preocupação, desvelo, solicitude, diligência, atenção, bom trato. A atitude de cuidado pode provocar preocupação, inquietação e sentido de responsabilidade (Boff, 1999). Essas aproximações nos permitem refletir sobre a ação clínica que possa considerar a pessoa que sofre, principalmente no contexto hospitalar, onde a doença - e não o doente - e o restabelecimento da vida a qualquer custo, muitas vezes é prioridade. A possibilidade de dar novos sentidos à vida a partir do confronto com a sua condição de ser-para-a-morte nos parece fundamental para uma ação clínica preocupada, sobretudo, com a ética que valorize o humano.

Concordamos com Safra (2004) quando aborda o fato de que resgatar a "ética do ser" requer ultrapassar regras de comportamento e apropriar-se do modo como o acontecer humano emerge no decorrer do seu percurso. Esses são elementos fundamentais que possibilitam habitar no mundo e, na medida em que a situação clínica é caracterizada pelo cuidado, entendemos a clínica como essencialmente ética, uma ética que “(...) desvela-se como beleza, como verdade, como dignidade, como presença de si e do outro" (p. 27). Nessa medida, a ética é a própria clínica.

Intervir diante do "terror" causado pelo adoecimento e pela vivência da hospitalização nos leva a refletir sobre o sentido de clínica, compreendida em sua origem - klinike - como "o que se faz junto ao leito". Nessa perspectiva, como modalidade de intervenção, "estar junto" é a possibilidade de ofertar um lugar de acolhimento para o paciente e seu cuidador/familiar, na medida em que, como dito por Safra (2006b), o acolhimento em uma comunidade - o lar -, necessário à condição humana, favorece o "ir" na descoberta e o "voltar" para um lugar seguro, mesmo que seja invisível aos olhos.

Considerando que quanto menor é a frequência do paciente em situações de grupo menos contato este realiza com as pessoas que fazem parte do seu meio social (Santana e cols., 2008), o suporte familiar e um contexto social adequado são reconhecidos como ferramentas importantes na melhora da autoconfiança e satisfação do paciente com o tratamento, bem como favorecem a reabilitação vocal e o equilíbrio emocional. Entre os pacientes que realizam o tratamento para o câncer de laringe, $45 \%$ são diagnosticados com depressão e ansiedade, sendo o primeiro mês, um período de ansiedade intensa para pacientes e familiares, tamanha é a incerteza do tratamento e a possibilidade de complicações (Ramírez e cols., 2003).
Ainda em relação ao suporte familiar, Barbosa e cols. (2004) identificaram que a retaguarda familiar suportiva apresenta-se como uma variável de extrema importância e favorece o enfrentamento de todo o tratamento. Do mesmo modo, observaram que nos pacientes para os quais esta retaguarda não foi oferecida, o enfrentamento e o manejo das dificuldades inerentes à doença, à LT e ao tratamento foram mais penosos.

Diante da interrupção de um cotidiano planejado, do adiamento de projetos e com a vivência de sentimentos de perdas causado pelo adoecimento, anuncia-se a condição de finitude que o diagnóstico de câncer carrega. A esse respeito, parece haver um consenso na literatura e diversos autores (Aarstad, Aarstad, Heimdal, \& Olofsson, 2005; Barbosa e cols., 2004; Braz e cols., 2005; Ramírez e cols., 2003; Santos, 2004) indicam a importância de se considerar aspectos ligados a ansiedade e depressão desde o momento do diagnóstico oncológico, principalmente quando o paciente necessita de internação hospitalar: "A adaptação foi o mais difícil. Acordar sem voz é duro (...) Tive que ter muito apoio da minha família, dos amigos, dos médicos pra ficar motivado" (Laringectomizado).

Diante de tantas repercussões, parece haver a necessidade do sujeito buscar e re-inventar os seus modos de viver. Como remarca Francisco (2005), se estamos diante de um evento em que o sujeito é convocado a inventar uma nova maneira de ser é, sobretudo, pela via do resgate do afeto que esta invenção será possível, através da alegria de viver, de amar, de compartilhar, de estender os braços para ajudar e abraçar as pessoas que nos cercam. Atos aparentemente simples, mas reconhecidos como caminhos para o resgate de nossa condição humana.

É necessário que as pessoas envolvidas em um processo de adoecimento possam dispor de um ambiente suportivo e que possibilite o acolhimento do sofrimento do paciente. Considerando este ponto de vista, é indispensável que a assistência psicológica estenda-se a pacientes, cuidadores/familiares e, também, a toda a equipe envolvida no processo de cuidar.

Diante da necessidade de amparo e, ao mesmo tempo, do sentimento de desproteção vivenciado pelo paciente, o diálogo assume papel primordial na medida em que visa o estabelecimento de um solo comum para o encontro (Gadamer, 2006) entre quem desempenha cuidados e quem é cuidado.

O meu sonho é que ele falasse mesmo como os outros falam (...) Porque é muito feio o som (...) E ele falando melhor (...) ele pode andar mais tranquilo pra fazer as coisinhas dele (...) Mas quando a pessoa é acostumada a trabalhar não consegue ficar dentro de casa (...) Eu tinha muita pena dele(...) Ele sofreu muito (...) ele ia falar com os netinhos dele e os netos não entende (...) Essa semana ele chorou foi muito com um vizinho lá. O menino chegou dizendo pra vó: - Vovó, vovó, vá lá na casa de Dona N. que seu M. falou! Aí ela veio: - N. meu menino tá dizendo que seu M. falou. Falou? Ai ele ouviu e chorou foi muito, ficou emocionado porque todo mundo já tá entendendo o que ele fala (Cuidadora). 
Compreender é possível através do ouvir, do sentir, do esperar, do acolher e do tocar. Sobretudo em momentos em que estamos fragilizados ou desorganizados internamente, provavelmente a ação mais organizadora seja a exposição ao outro através do afeto, que nada mais é do que uma declaração de amor, silenciosa, expressa na ação (Schettini, 2007). A esse respeito, o conceito de placement, proposto inicialmente por Winnicott (1987), parece-nos bastante adequado na medida em que se dispõe a oferecer, fundamentalmente, um "lugar" de sustentação para a pessoa que sofre. Um lugar sustentado por um outro, em que o humano poderá destinarse a um horizonte possível e proporcionar ao paciente uma situação que possa responder às suas reais necessidades durante o tratamento.

Mainha, a sra vá falando devagarzinho que a gente vai entender. Ai a gente ia praticando (...) ela ia falando e agente entendendo (...) foi aí que a gente se acostumou com ela. A gente ficou treinando (...). Eu e meus irmãos tudinho (...) porque "agente" é tudo doido por ela (riso tímido) (Cuidadora).

Segundo Safra (2006a), enquanto modalidade de intervenção, a clínica busca a possibilidade de colocar o indivíduo em uma situação que possa dar contorno às suas necessidades, antes satisfeitas no seu "lugar" originário. Vale salientar que não se trata de favorecer uma experiência emocional corretiva, mas de possibilitar uma nova forma de se posicionar frente ao ocorrido. Para isso, faz-se mister um diagnóstico rigoroso das reais necessidades do paciente naquele momento, levando em consideração a sua singularidade e o ambiente em que está inserido.

Ramírez e cols. (2003) acompanharam, na Espanha, um grupo de 62 pacientes com câncer de cabeça e pescoço por um período de 36 meses. Observaram que, desses pacientes, 55\% realizaram a LT e, entre eles, apenas $15 \%$ conseguiram retornar ao trabalho. Os outros $45 \%$ realizaram modalidades cirúrgicas menos invasivas (laringectomia supraglótica horizontal e vertical) e, nesse grupo, mais de 50\% conseguiu retomar suas atividades profissionais.

Hoje eu fico chamando ele pros cantos pra ele não ficar em casa sem fazer nada. Quando ele fica muito tempo só ele fica deprimido (...) Eu vejo, eu fico estimulando pra ele andar, pra ir pros cantos. Porque ele não pode mais trabalhar como antes e o distraimento da pessoa é trabalhar (...) num pode mais. E quem quer ajudar? Só a gente mesmo que é da família que não tem frescura (Cuidadora).

Percebe-se que, muito embora os pacientes possam obter recursos governamentais, tais como a aposentadoria para prover as suas necessidades, o trabalho assume uma outra dimensão para além da subsistência, apresentando-se, para a maioria dos entrevistados, como um modo de sentir-se útil e integrado socialmente.

Compreendendo que o adoecimento provoca verdadeiras fraturas na vida do paciente, a hospitalização, paradoxalmente, parece não ofertar um lugar em que o indivíduo sinta-se seguro. O cuidado voltado a este paciente será tomado como a possibilidade de oferecer um lugar em que seja possível, apesar da doença, dar sentido ao existir. O confronto humano com as adversidades da vida e principalmente em relação a sua condição de finitude revela que a sustentação, doada através da relação com o outro, é fundamental.

O momento do diagnóstico é crítico para a maioria dos pacientes e seus respectivos acompanhantes. Como destacam Defina, Massih e Mamede (2004), é um momento em que muitos não absorvem as informações passadas pela equipe e, diante de uma extrema dificuldade de ouvir, é comum interpretarem as informações de forma confusa e equivocada.

Bom, pra mim (...) assim, na hora eu não tive reação (...). Eu só pensava nela, em acalmá-la, em não deixar ela se desesperar, mostrando uma tranqüilidade que eu não tinha na hora, né? Mas depois eu consegui passar ultrapassar esse, esse, esse desespero todo. Ai agora a gente já está mais tranqüilo. (...) o que a gente conversava era sobre como lidar com ela, ter paciência com ela, cuidados com ela (Cuidadora).

No percurso da vida, determinadas situações, como é o caso do adoecimento e da iminência de morte, produzem verdadeiras rupturas na vida de uma pessoa. Ao homem é dada a possibilidade de existir em um mundo paradoxal: "estar" para nascer, "estar" para morrer; "estar" ao encontro, "estar" ao desencontro. $\mathrm{O}$ adoecimento e a hospitalização retiram o indivíduo do "seu" lugar de segurança trazendo a iminência de rupturas traumáticas e a morte escancarada intensifica a vivência desses sofrimentos.

\section{Considerações finais}

Voltar-se à experiência dos pacientes e de seus cuidadores e familiares por meio da análise de suas narrativas, revelou o quanto é importante dirigir esta fala/sofrimento para alguém, pois, na medida em que é endereçado, o sofrimento ganha continente, contorno, torna-se humano porque é compartilhável. A experiência do adoecimento e das repercussões advindas da LT são extremamente ricas de sentidos: des-armando, des-preocupando para ocupar-se com o que interessa e realmente está presente no aqui e agora, pedindo espaços de amparo onde o abdicar de si implica em abrir-se para outro. Os achados de nossa pesquisa estão de acordo com a literatura, principalmente aquela que aborda o impacto emocional negativo advindo do diagnóstico do câncer e dos seus tratamentos.

Os pacientes entrevistados traziam um profundo sofrimento que se apresentava não somente como dor física, mas, 
principalmente, pelas sequelas psicossociais resultantes de um procedimento que os afastam da ambiência construída ao longo da vida: do lar, de familiares, de amigos, do trabalho, contribuindo para o seu isolamento e a vivência de um sofrimento velado e interditado. $\mathrm{O}$ medo da morte não pareceu estar relacionado apenas a uma questão física, mas denuncia uma sensação de verdadeiro terror frente à ruptura das relações com os outros humanos.

Frente a tantas repercussões, a família sofre duplamente: por meio do impacto do diagnóstico, que traz consigo a simbologia de uma sentença de morte e face à necessidade de adaptações abruptas que, em muitos casos, transcendem os seus limites físicos, emocionais, sociais e financeiros. As questões ligadas à hospitalização, especialmente aquelas relacionadas às alterações decorrentes da intervenção cirúrgica, irão impor mudanças significativas à organização familiar, rompendo com papéis pré-estabelecidos, conquistados e valores, muitas vezes patriarcais.

Especificamente em relação às narrativas, podemos inferir que a fragilidade nos vínculos afetivos e nos laços sociais e econômicos são aspectos que podem negligenciar o cuidado direcionado aos laringectomizados. Diante disso, além dos pacientes, considerar a família e/ou cuidadores como parte integrante do tratamento pode favorecer sua adaptação frente às novas demandas, criando um espaço para expor ansiedades, angústias e sofrimentos diante deste momento de crise que pede novos sentidos.

De fato, o cuidador desenvolve uma multiplicidade de tarefas difíceis, repetitivas, solitárias e desgastantes (Floriani \& Schramm, 2006). Além disso, muito embora tenhamos investigado relatos de apenas quatro cuidadoras, nosso estudo evidenciou uma realidade bem comum: mulheres cuidadoras.

Aspectos econômicos, sociais, antropológicos, culturais e psicológicos podem reverberar nas questões ligadas ao gênero do cuidador. Entretanto, Carvalho, Cavalcanti, Almeida e Bastos (2008) destacam que a maioria dos cuidadores ser do gênero feminino, não é uma realidade tão atual, mesmo assim, vivemos um momento de profundas mudanças e que mantém questionamentos em aberto, pois envolvem a participação de diversas disciplinas e saberes. Nesse contexto, outros estudos sobre a temática podem ampliar o conhecimento de uma realidade específica que favoreçam medidas de amparo e cuidado a esse personagem que também se torna vulnerável as diversas formas do adoecer, sejam elas biológicas, psicológicas ou sociais.

A nosso ver, a utilização do trabalho com grupos em hospitais é uma alternativa eficaz no apoio e suporte emocional e, frente à grande demanda encontrada no sistema público de saúde, pode favorecer o suporte a um maior número de pacientes. Levando em consideração as narrativas dos familiares/cuidadores, sugerimos que este trabalho possa ser estendido a estas pessoas que, por estarem em contato direto com os pacientes, são circundados por uma diversificada e intensa carga de sentimentos que recebem do paciente somando-se às suas próprias.

Ao longo dessa pesquisa, uma reflexão de grande relevância esteve presente: muito desse sofrimento poderia ser evitado.
Com os grandes avanços na área médica, já se sabe, por exemplo, que determinados hábitos e comportamentos são danosos, agridem o nosso organismo e favorecem o surgimento de diversas doenças, causando verdadeiras epidemias de morbidade e mortalidade prematuras. No caso do câncer de laringe, o uso contínuo de álcool e, principalmente, o tabagismo nos fazem pensar sobre a importância de ações educativas e preventivas em todos os setores sociais de um modo mais intensivo e frequente, o que requer não somente o incremento de políticas públicas, mas a mobilização de diversos profissionais em uma caminhada interdisciplinar.

Outro fato relevante que marcou nossa trajetória, muito embora não fosse objetivo inicial da nossa pesquisa, foi poder observar, de perto, a intensidade com a qual a equipe de saúde é afetada. Faz-se necessário, nesse contexto, criar espaços de discussão que propiciem avaliar e propor estratégias focadas na atenuação da carga emocional vivenciada pelos profissionais diante das suas expectativas e frustrações inerentes aos tratamentos.

Por se tratar de uma pesquisa qualitativa, o estudo apresenta limitações na generalização dos seus resultados que possam estar ligados a diagnósticos e reações psicopatológicas dos participantes. Após a análise dos dados, ficou claro que a intensidade dessas reações experimentadas pelos pacientes e seus cuidadores interferem no seu tratamento e demandam mais atenção da equipe de saúde.

Temos plena convicção que a nossa trajetória não chegou ao fim e outros estudos e reflexões são necessários para que possamos melhor compreender essas tantas facetas que envolvem o humano, sem aprisioná-lo e considerando-o em sua singularidade múltipla. No entanto, podemos afirmar que o contato com esses pacientes e a busca de compreensão de seus sofrimentos leva-nos, cada vez mais, a tomar a ética do cuidado como o principal referencial em ações que englobam aspectos biopsicossociais e envolvem todos os profissionais de saúde que trabalham na assistência.

\section{Referências}

Aarstad, H. J., Aarstad, A. K. H., Heimdal, J. H., \& Olofsson, J. (2005). Mood, anxiety and sense of humor in head and neck cancer patients in relation to disease stage, prognosis and quality of life. Acta Oto-Laryngológica, 125, 557-565.

Arrànz, P., \& Coca, C. (2003). Intervención psicológica em um servicio de hemato-oncología. In E. Remor, P. Arrànz, \& S. Ulla (Orgs.), El psicólogo em el âmbito hospitalario (pp. 641-678). Bilbao, España: Editorial Desclée de Brouwer.

Barbosa, L. N. F., Francisco, A. L., \& Efken, K. H. (2007). Adoecimento: O ser-para-a-morte e o sentido da vida. Pesquisas e Práticas Psicossociais, 2(1), 54-60.

Barbosa, L. N. F., Santos, D. A., Amaral, M. X. F., Gonçalves, A. J., \& Bruscato, W. L. (2004). Repercussões psicossociais em pacientes submetidos à laringectomia total por câncer de laringe: Um estudo clínico-qualitativo. Revista SBPH, 7(1), 45-58. 
Birgin, D. (2004). Afectos y família: La família del paciente oncológico. In L. Aresca, D. Birgin, \& S. Blum, Psiconcología: Diferentes miradas (pp. 27-41). Buenos Aires: Lugar.

Björklund, M., Sarvimäki, A., \& Berg, A. (2008). Health promotion and empowerment from the perspective of individuals living with head and neck cancer. European Journal of Oncology Nursing, 12, 26-34

Boff, L. (1999). Saber cuidar: Ética do humano, compaixão pela terra. Petrópolis, RJ: Vozes.

Braz, D. S. A., Ribas, M. M., Dedivitis, R. A., Nishimoto, I. N., \& Barros, A. P. B. (2005). Quality of life and depression in patients undergoing total and partial laryngectomy. Clinics, 60, 135-142.

Carvalho, A. M. A., Cavalcanti, V. R. S., Almeida, M. A., \& Bastos, A. C. S. (2008). Mulheres e cuidado: Bases psicobiológicas ou arbitrariedade cultural? Paidéia (Ribeirão Preto), 18, 431-444.

Defina, A. P., Massih, D. A., \& Mamede, R. C. M. (2004). Relato de experiência da atuação da fonoaudiologia e da psicologia a pacientes com câncer de cabeça e pescoço. Revista Brasileira de Cirurgia de Cabeça e Pescoço, 33, 45-48.

Derks, W., Leeuw, J. R. J., Hordijjk, G. J., \& Winnubst, J. A. M. (2005). Differences in coping style and locus of control between older and younger patients with head and neck cancer. Clinical Otolaryngology and Allied Sciences, 30, 186-192.

Flávio, P. G. C., \& Zago, M. M. F. (1999). Reabilitação vocal do laringectomizado: Características culturais do processo. Revista Latino-americana de Enfermagem, 7, 63-70.

Floriani, C. A., \& Schramm, F. R. (2006). Cuidador do idoso com câncer avançado: Um ator vulnerado. Cadernos de Saúde Pública, 22, 527-534.

Francisco, A. L. (2005). Resgatando o afeto. Boletim de Psicologia, 55, 169-176.

Gadamer, H. G. (2006). O caráter oculto da saúde (A. L. Costa, Trad.). Petrópolis, RJ: Vozes.

Gonçalves, A. J., Menezes, M. B., \& Bertelli, A. A. T. (2005). Câncer de laringe. In A. J. Gonçalves, \& F. A. M. C. Alcadipani, (Orgs). Clínica e cirurgia de cabeça e pescoço (pp. 232-254). São Paulo: Tecmedd Editora.

Instituto Nacional de Câncer. Ministério da Saúde. Secretaria de Atenção a Saúde. Coordenação de prevenção e vigilância. (2005). Estimativa 2006: Incidência de câncer no Brasil. Rio de Janeiro: INCA.

Ismael, S. M. C. (2007). Efetividade da terapia cognitivocomportamental na terapêutica do tabagista. Tese de doutorado não publicada, Faculdade de Medicina, Universidade de São Paulo, São Paulo.

Lotempio, M. M., Wang, K. H., Sadeghi, A., Delacure, M. D., Juillard, G. F., \& Wang, M. B. (2005). Comparison of quality outcomes in laryngeal cancer patients following chemoradiation vs. total laryngectomy. Otolaryngology: Head ands Neck Surgery, 132, 948-953.
Minayo, M. C. S. (2004). O desafio do conhecimento: Pesquisa qualitativa em saúde (8a ed.). São Paulo: Hucitec.

Ministério da Saúde. (2007). Integração de informações dos registros de câncer brasileiros. Revista de Saúde Pública, 41, 865-868.

Nemr, K., \& Ramozzi-Chiarottino, Z. (2002). Fatores cognitivos na reabilitação vocal após laringectomia total. Revista Brasileira de Otorrinolaringologia, 68, 805-810.

Noto, A. R. N., \& Galduróz, J. C. F. (1999). O uso de drogas psicotrópicas e a prevenção no Brasil. Ciência \& Saúde Coletiva, 4, 145-151.

Ramírez, M. J. F., Ferriol, E. E., Doménech, F. G., Llatas, M. C., Suárez-Varela, M. M., \& Martínez, R. L. (2003). Psychosocial adjustment in patients surgically treated for laryngeal câncer. Otolaryngology: Head and Neck Surgery, 129, 92-7.

Santana, J. J. R. A., Zanin, C. R., \& Maniglia, J. V. (2008). Pacientes com câncer: Enfrentamento, rede social e apoio social. Paidéia (Ribeirão Preto), 18, 371-384.

Safra, G. (2004). A pó-ética na clínica contemporânea. Aparecida, SP: Idéias \& Letras.

Safra, G. (2006a). Placement: Modelo clínico para o acompanhamento terapêutico. Psychê, 18, 13-20.

Safra, G. (2006b). Situação clínica e mal-estar contemporâneo: Da técnica à ética [DVD's 1,2 e 3 da Série: Profoco Programa de Formação Continuada com o Prof. Gilberto Safra]. São Paulo: Edições Sobornost.

Santos, D. A. (2004). A atuação do psicólogo junto a pacientes cirúrgicos com câncer de cabeça e pescoço. In W. L. Bruscato, C. Benedetti, \& S. R. A. Lopes (Orgs.), A prática da psicologia hospitalar na Santa Casa de São Paulo: Novas páginas em uma antiga história (pp. 167-176). São Paulo: Casa do Psicólogo.

Schettini, L. (2007). A coragem de conviver: Uma forma de organizar as relações interpessoais. Petrópolis, RJ: Vozes.

Sociedade Brasileira de Cancerologia (2007). De cabeça e pescoço. Recuperado em 5 março 2010, de http://www. sbcancer.org.br/final/artigossetor.asp?idart $=5$

Turato, E. R. (2003). Tratado de metodologia da pesquisa clínico-qualitativa: Construção teórico-epistemológica, discussão comparada e aplicação nas áreas da Saúde e Humanas (2a ed.). Petrópolis, RJ: Vozes.

Vickery, L. E., Latchford, G., Hewinson, J., Bellew, M., \& Feber, T. (2003). The impact of head and neck cancer and facial desfigurement on the quality of life of patients and their partners. Head \& Neck, 25, 289-296.

Winnicott, D. D. (1987) Privação e delinquência (A. Cabral, Trad.). São Paulo: Martins Fontes. 
Barbosa, L. N. F., \& Francisco, A. L. (2011). Laringectomizados: ação do psicólogo.

Leopoldo Nelson Fernandes Barbosa é psicólogo, doutorando em Neuropsiquiatria e Ciências do Comportamento pela Universidade Federal de Pernambuco.

Ana Lúcia Francisco é Professora Doutora da Universidade Católica de Pernambuco - UNICAP.

Recebido: 15/01/2009

$1^{a}$ revisão: 19/03/2009

$2^{a}$ revisão: $12 / 12 / 2009$

Aceite final: $02 / 01 / 2010$ 